\title{
Effects of filter choice in GT3X accelerometer assessments of free-living activity
}

\author{
Wanner, Miriam ; Martin, Brian W ; Meier, Flurina ; Probst-Hensch, Nicole ; Kriemler, Susi
}

\begin{abstract}
PURPOSE: ActiGraph accelerometers are widely used devices to objectively assess physical activity. The GT3X version has two filter options to be selected before data assessment (normal and low-frequency extension filter option). It is not clear whether the resulting physical activity levels differ depending on the choice of the filter. The aims were to compare GT3X data collected using the different filter options during free-living activities and to establish correction factors if the results were not comparable. METHODS: Sixty-five participants of the population-based SAPALDIA-cohort $(50.8 \%$ women, age range $=40-80 \mathrm{yr}$ ) wore two GT3X accelerometers with different filter selections simultaneously during 8 d. Spearman correlations, Wilcoxon rank sum tests, McNemar tests, scatter plots, and Bland-Altman plots were used to compare the data. Correction factors were established using linear regression models. RESULTS: Although Spearman correlations were high ( $\mathrm{r}$ 0.93), there were significant differences in minutes per day between filter options for nonwearing time and time spent in sedentary, light, and moderate-to-vigorous physical activity (all $\mathrm{P}<0.001$ ), with more remarkable differences in the lower range of activity (sedentary and light activities). Mean counts per minute and steps per day were significantly higher using the low-frequency extension filter $(\mathrm{P}<0.001)$. Most differences could be resolved using the correction factors. CONCLUSIONS: The observed differences are especially important when research is focusing on sedentary and light activities. In future studies, it is important to carefully evaluate the suitable filter option and to specify the filter choice in publications. The correction factors can be used to make data assessed using the low-frequency extension filter comparable to data assessed using the normal filter option.
\end{abstract}

DOI: https://doi.org/10.1249/MSS.0b013e31826c2cf1

Posted at the Zurich Open Repository and Archive, University of Zurich

ZORA URL: https://doi.org/10.5167/uzh-69558

Journal Article

Originally published at:

Wanner, Miriam; Martin, Brian W; Meier, Flurina; Probst-Hensch, Nicole; Kriemler, Susi (2013). Effects of filter choice in GT3X accelerometer assessments of free-living activity. Medicine and Science in Sports and Exercise, 45(1):170-177.

DOI: https://doi.org/10.1249/MSS.0b013e31826c2cf1 
Title: Effects of filter choice in GT3X accelerometer assessments of free-living activity

Miriam Wanner ${ }^{1)}$, Brian W Martin ${ }^{1)}$, Flurina Meier ${ }^{2,3)}$, Nicole Probst-Hensch ${ }^{2,3)}$, Susi Kriemler $^{1,2,3)}$

Affiliations:

1) Physical Activity and Health Work Unit, Institute of Social and Preventive Medicine, University of Zurich, Zurich, Switzerland

${ }^{2)}$ Department of Epidemiology and Public Health, Swiss Tropical and Public Health Institute, Basel, Switzerland

${ }^{3)}$ University of Basel, Basel, Switzerland

Corresponding author:

Susi Kriemler

Physical Activity and Health Work Unit, Institute of Social and Preventive Medicine, University of Zurich

Seilergraben 49

CH-8001 Zurich

Switzerland

Phone: +41 446345548

Fax: +41 446345185

susi.kriemler@unibas.ch 
Running title: Filter choices in GT3X accelerometers

Funding source:

This study was part of the SAPALDIA Study. The SAPALDIA Study is supported by grants from the Swiss National Science Foundation (grants no 3347CO-108796/1, 3247BO-104283, 3247BO-104288, 3247BO-104284, 32-65896.01, 32-59302.99, 32-52720.97, 32-4253.94, 4026-28099, PDFMP3-123171), by the Federal Office for Forest, Environment and Landscape, the Federal Office of Public Health, the Federal Office of Roads and Transport, the canton's government of Aargau, Basel-Stadt, Basel-Landschaft, Geneva, Ticino, and Zurich, Swiss Lung League, the canton's lung leagues of Basel Stadt/ Basel Landschaft, Geneva, Luzern, Ticino and Zurich.

Conflict of interest:

M Wanner has no conflict of interest.

BW Martin has no conflict of interest.

F Meier has no conflict of interest.

N Probst-Hensch has no conflict of interest.

S Kriemler has no conflict of interest. 


\begin{abstract}
Purpose: Actigraph accelerometers are widely used devices to objectively assess physical activity. The GT3X version has two filter options to be selected prior to data assessment (normal and low frequency extension filter option). It is not clear whether the resulting physical activity levels differ depending on the choice of the filter. The aims were to compare GT3X data collected using the different filter options during free-living activities and to establish correction factors if the results were not comparable.
\end{abstract}

Methods: 65 participants of the population-based SAPALDIA-cohort (50.8\% women, age range 40-80 years) wore two GT3X accelerometers with different filter selections simultaneously during 8 days. Spearman correlations, Wilcoxon rank sum tests, McNemar tests, scatter plots and Bland Altman plots were used to compare the data. Correction factors were established using linear regression models.

Results: Although Spearman correlations were high $(r>0.93)$, there were significant differences in minutes per day between filter options for non-wearing time, and time spent in sedentary, light, and moderate-to-vigorous physical activity (all $\mathrm{p}<0.001$ ) with more remarkable differences in the lower range of activity (sedentary and light activities). Mean counts/minute and steps per day were significantly higher using the low frequency extension filter $(\mathrm{p}<0.001)$. Most differences could be resolved using the correction factors.

Conclusions: The observed differences are especially important when research is focusing on sedentary and light activities. In future studies, it is important to carefully evaluate the suitable filter option and to specify the filter choice in publications. The correction factors can be used to make data assessed using the low frequency extension filter comparable to data assessed using the normal filter option.

Key words: Actigraph, physical activity, low frequency extension, sedentary behavior 


\section{Introduction}

Paragraph number 1 The assessment of physical activity using objective devices such as accelerometers has increased in popularity (7). However, different accelerometers are being used and even if using the same monitors differences in firmware versions may limit comparability (21). The Actigraph accelerometer is a widely used accelerometer to objectively measure physical activity $(15,21)$. The model GT3X is a triaxial device that also includes a step counter and an inclinometer. The device has a digital filter that limits the sampling to the frequency range of 0.25 to $2.5 \mathrm{~Hz}$ to detect normal human motion (GT3X specifications on www.theactigraph.com). The low frequency extension filter option is a data collection option that extends the lower end of the filter cut-off (2). According to the manufacturer, this option is useful when measuring actigraph data for individuals who move slowly or take very light steps, such as the elderly (2). More details on the two filter options are not available.

Paragraph number 2 Most studies using the GT3X do not specify the filter option used for data collection. However, it is not clear whether data from different studies are comparable if different filter options were used. If the data were not comparable, a correction factor may be helpful in order to compare data assessed with different filter options.

Paragraph number 3 The aims of this study were therefore 1) to compare GT3X data collected using the normal and the low frequency extension filter during eight days of freeliving activity, and 2) if needed, to establish correction factors for the different accelerometer outcome variables to make data comparable between the two filter options.

\section{Methods}

Study design, procedure and participants 
Paragraph number 4 The present study was part of a large cohort study in Switzerland (SAPALDIA, Swiss Cohort Study on Air Pollution and Lung and Heart Disease in Adults (1)) which recruited cohort members from the general population aged 18 to 61 years at baseline in 1991. During the third follow-up of the study in 2010/2011, a sub sample of 65 participants (age range 40-80 years) was recruited for the validation of a physical activity questionnaire using accelerometers and was asked to wear two accelerometers simultaneously for 8 consecutive days. Participants were requested to wear the two accelerometers close to each other, but the order of placement was not defined. One accelerometer was initialized selecting the normal and one selecting the low frequency extension filter. First instructions were given during the recruitment procedure in the study centers, detailed instructions were given by telephone and the accelerometers were sent and returned by postal mail. All participants had to complete a written signed consent form. The study was approved by the ethical committees of the respective study regions.

\section{Measurements}

Paragraph number 5 Accelerometers of the type ActiGraph GT3X (ActiGraph, Pensacola, FL, USA) were used. These devices measure accelerations ranging in magnitude from $0.05 \mathrm{~g}$ to $2.5 \mathrm{~g}$. The accelerometer output is digitized by a 12-bit analog-to-digital convertor at a rate of $30 \mathrm{~Hz}(2)$. The signal then passes through a digital filter that band-limits the accelerometer to the frequency range of 0.25 to $2.5 \mathrm{~Hz}$. The filtered signal is integrated over a user-specific interval called epoch time.

Paragraph number 6 One accelerometer was initialized using the normal filter option, the other one using the low frequency extension filter option with otherwise identical initializing parameters. These included an epoch time of $5 \mathrm{~s}$ which were re-integrated to $60 \mathrm{~s}$ for analyses and firmware version 4.4. The Actilife 5 software was used to initializes and download the accelerometers (www.theactigraph.com/products/actilife). The two devices were attached to 
an elastic belt one next to the other and individuals were instructed to wear them on the right hip during waking hours.

\section{Data analysis}

Paragraph number 7 The uniaxial accelerometer data (vertical axis) was used in these analyses. In order to classify accelerometer output data into different physical activity intensity categories, cut-offs were used as follows. Minutes per week spent in sedentary $(<150$ counts/minute) (12), light (150-2019 counts/min), and moderate-to-vigorous $(\geq 2020$ counts/min) physical activity (18) were calculated as well as the number of steps per day. Non-wearing time was defined as 60 or more minutes of consecutive zeros. Minutes spent in bouts of 10 or more minutes (allowing for 2 minutes below threshold) in moderate-tovigorous physical activity were calculated. The MeterPlus software (Santech Inc., version 4.2, www.meterplussoftware.com) was used to clean the data and to calculate individual summary variables.

Paragraph number 8 Spearman correlations were calculated between data assessed with the normal and with the low frequency extension filter. For sensitivity analyses, two additional cut-offs to distinguish between sedentary and light activities were used (100 counts/min (17), 200 counts/min (4)), because differences between the filter options were mostly expected in the low frequency range (sedentary and light activities). The Wilcoxon rank sum test was used to test whether the mean difference between data assessed with the two filter options was significantly different from 0 . Scatter plots with identity lines were used to display the correlations and Bland-Altman plots to show the extent of agreement between the two filter options. Proportions were calculated for meeting physical activity recommendations (at least $150 \mathrm{~min} /$ week of moderate-to-vigorous physical activity (29)) and steps recommendations (at 
least 8'000 and 10'000 steps/day, respectively (26)) and the McNemar test was used to compare proportions between the two filter options. Statistical significance was set to $\mathrm{p}<0.05$.

Paragraph number 9 In a second step, a random sample of 33 of the 65 participants was drawn and correction factors were calculated for the output variables that were significantly different between the two filters (mean counts/minute, steps/day, non-wearing time and time spent in sedentary, light, moderate-to-vigorous physical activity including bouts) using linear regression models. These correction factors were then used to recalculate the corresponding results from the low frequency filter devices in the remaining sample $(\mathrm{N}=32)$ and compared to the normal filter data of that sub sample using Spearman correlations, scatter plots with identity lines, Wilcoxon rank sum tests and McNemar tests. STATA IC version 11 was used for statistical analyses (StataCorp LP, College Station, Texas, 2009).

Paragraph number 10 In order to check whether the established correction factors can also be used for data analyzed using other widely used cut-offs, we re-analyzed the data using Freedson cut-offs (8) and re-applied the correction factors to that data.

\section{Results}

Paragraph number 11 Of the 65 participants, 33 were women $(50.8 \%)$. The mean age was 60.8 years (SD 9.9 years) and the age range was 40 to 80 years. Mean BMI was $26.6 \mathrm{~kg} / \mathrm{m}^{2}$ (95\%-CI: 25.6 to 27.6).

Paragraph number 12 Table 1 describes the comparison between the two filter options. Spearman correlations were high $(r>0.93)$ for all outcome variables. The mean difference was large for sedentary time (+25.7 $\mathrm{min} /$ day $)$ and for light activities $(-31.5 \mathrm{~min} /$ day $)$; the respective mean differences as percent of time recorded by the normal filter device for sedentary time and time spent in light activities were $4.5 \%$ and $-13.4 \%$, respectively. On the other hand, the mean difference for moderate-to-vigorous physical activity was small $(-3.1$ 
min/day), but this difference as percent of time spent in moderate-to-vigorous activities recorded by the normal filter device was larger (-21.3\%). Mean counts/minute and steps/day were higher using the low frequency extension filter. All differences were statistically significant according to the Wilcoxon test. Changing the cut-offs for sedentary behavior to 100 counts/minute and 200 counts/minute, respectively, did not change the results (data not shown).

Paragraph number 13 Figure 1 and Supplemental Digital Content (SDC) Figure 1 show the scatter plots for the comparison of outcome variables assessed with the different filter options (left side: without correction, right side: with correction of the low frequency extension outcome variables, see below).

Paragraph number 14 Even though the correlations were high (see Table 1), the identity lines show that non-wearing and sedentary time were systematically lower and time spent in light and moderate-to-vigorous physical activity systematically higher according to the low frequency compared to the normal filter (Figure 1 and SDC Figure 1, left side). Mean counts per minute (SDC Figure 1a) and steps/day (Figure 1a) were higher when assessed with the low frequency extension option with a remarkable difference for the latter.

Paragraph number 15 Bland-Altman plots are displayed in Figure 2 and SDC Figure 2. These plots support the fact that non-wearing and sedentary time were systematically lower and time spent in light and in moderate-to-vigorous physical activity systematically higher according to data assessed with the low frequency extension filter option compared to the normal filter option. Furthermore, linear regression showed that for the mean counts/minute and the number of steps per day there was an association between the mean and the difference, with higher means resulting in larger (negative) differences (coefficient for counts/minute $=0.034$, $\mathrm{p}=0.048$; coefficient for steps $/ \mathrm{day}=0.33, \mathrm{p}<0.001$ ). 
Paragraph number 16 The correction factors for the different accelerometer outcome variables are presented in Table 2. Figure 1 and SDC Figure 1 (right side) as well as Table 3 present the comparisons of the outcome variables from the remaining sample by applying these correction factors to the data assessed with the low frequency extension filter. Graphically it is obvious that the correction factors help to harmonize the data which are now more evenly spread around the line of identity than in Figure 1 and SDC Figure 1 (left side). Furthermore, Table 3 shows that the data are more comparable after the correction factors were applied: The mean and median difference and the mean difference in percent are smaller than in Table 1, and the Wilcoxon rank sum test shows that for all accelerometer outcome variables except for moderate-to-vigorous physical activity the mean difference between filter options was not significantly different from zero.

Paragraph number 17 The proportion of participants achieving at least 8000 steps/day was $44.6 \%$ according to the normal filter and $98.5 \%$ according to the low frequency filter $(\mathrm{p}<0.0001)$. The proportion achieving at least $10^{\prime} 000$ steps/day was $18.5 \%$ according to the normal filter and $87.7 \%$ according to the low frequency filter $(\mathrm{p}<0.0001) .67 .7 \%$ (according to the normal filter) and $69.2 \%$ (according to the low frequency filter) reached at least 150 minutes/week of moderate-to-vigorous physical activity $(\mathrm{p}=0.32)$. We also compared the categorization of achieving at least 150 minutes/week of moderate-to-vigorous physical activity for the two filter options. Here, all but one individual $(1.5 \%)$ fell into the same category independent of the filter option. After applying the correction factors, there was no significant difference in the proportion meeting the steps recommendations between the two filter options (based on 8'000 steps/day (40.6 vs. $37.5 \%, \mathrm{p}=0.32)$ or 10 '000 steps/day (12.5 vs. $15.6 \%, \mathrm{p}=0.56))$.

\section{Discussion}


Paragraph number 18 The present study shows that in an adult population, results from the globally used Actigraph GT3X accelerometer varied significantly according to the filter option used. Differences were especially remarkable in the lower range of the activity spectrum (sedentary and light activities) and in mean steps per day. However, most differences could be resolved using correction factors developed based on linear regression. Even though physical activity research often focuses on moderate and vigorous intensity activity, a new focus on sedentary behavior has evolved over the past years, showing that sedentary behavior is a distinct risk factor for health independent of physical (in)activity (20, $23,24)$. On the other hand, even light-intensity activities have been shown to have favorable health effects, at least in older adults $(3,9)$. Replacing sedentary time with light-intensity activities may have a potential for health promotion (3). Therefore, the findings of the present study may especially play a role for research in the domain of sedentary behavior and lightintensity physical activity.

Paragraph number 19 Differences between the two filter options were not so much expected for moderate-to-vigorous intensity activities, as such activities usually do not consist of movements occurring at the lower end of the frequency range. Even though the differences between the two filter options were significant for moderate-to-vigorous physical activity (and remained significant even after applying the correction factor), these small differences are not meaningful with regard to their health impact (e.g. around 3 minutes difference out of 30 minutes) in populations that have activity levels comparable to the participants of the present study. Likewise, categorizing individuals into meeting or not meeting physical activity recommendations of at least 150 minutes/week of moderate-to-vigorous physical activity (29) did not yield different results based on filter choice. However, as the difference in percent of the moderate-to-vigorous activity time recorded by the normal filter was substantial $(>20 \%)$, the mean difference in minutes will be larger in more active populations. 
This may also be the case when moderate-to-vigorous activity time is expressed as a cumulative measure over the week as done in most physical activity guidelines or recommendations to prevent weight gain (6). In these instances, the correction factor may still be useful.

Paragraph number 20 The most remarkable difference was found for the number of steps per day. Depending on the filter choice, participants with a mean age of about 60 years spent 7700 (normal filter) and more than 15'000 steps/day (low frequency filter), respectively. Assuming a step length of 0.5 to 1 meter, this step difference equals a walking distance of 3.65 to 7.3 kilometers per day or 40 to 90 minutes of walking at a pace of 5 kilometer/hour. This is a large difference and most relevant as a difference of 1.6 kilometers in walking distance per day ( 1.6 versus $\geq 3.2$ kilometers/day) was associated with a relative risk of dying of 1.8 over 12 years in retired men (10). Walking more than 1 hour per day (compared to less than one hour) was furthermore associated with a longer life expectancy and a lower lifetime medical expenditure (19). Furthermore, individuals taking between 7500 steps and $<10$ '000 steps/day are considered as being somewhat active, while those taking $\geq 12^{\prime} 500$ steps/day are considered as being highly active (27). Therefore, our participants would on average be considered as somewhat active according to the normal filter but as highly active according to the low frequency filter. These examples show the public health relevance of the differences between the two filter options found in this study.

Paragraph number 21 The step outcomes when using the low frequency filter do not seem reasonable when put in relation to the time spent in light and moderate-to-vigorous physical activity and when compared with other populations (e.g. (28)). The Actigraph step function of an older version (model 7164) has been compared to observed steps taken and to pedometer counts. In a controlled setting (treadmill), the Actigraph model 7164 exactly counted (within $\pm 1 \%$ ) observed steps taken most of the time at different treadmill speeds, while some of the 
pedometers tended to underreport actual steps taken, especially at lower speeds (13). There was a high correlation between Actigraph model 7164 steps/day and Yamax pedometer steps/day $(\mathrm{r}=0.86, \mathrm{p}<0.0001)(25)$. However, due to the higher sensitivity of the Actigraph compared to pedometers for detecting steps during slow walking, the Actigraph 7164 also recorded more "erroneous" steps than the Yamax pedometer, for example under typical motor vehicle travelling conditions (14). This was supported by a mean difference between the devices of $1845 \pm 2116$ steps/day in free-living individuals (Actigraph $>$ Yamax, $\mathrm{p}<0.0001$ ) (25). The only study comparing the GT3X step count function with pedometers that we found was carried out in pregnant women (5). In that study, the GT3X underreported actual steps taken by up to $21 \%$, especially during slower walking speeds (5). On the other hand, it is likely that the low frequency filter extension in our study increased the sensitivity of the GT3X step count function too much leading to an overcorrection of the reality (e.g. by detecting steps at the very low activity level or during motor vehicle transport). Steps can be useful to follow changes in physical activity behavior. If steps are used in relation to meeting recommendations, it is important to specify the instrument that was used to assess the number of steps. A comparison of steps recorded by the Actigraph GT3X with the two filter options and with observed number of steps could shed light on the validity of the GT3X step count function using different filter options in a future study.

Paragraph number 22 The correction factors established based on linear regression were useful to convert the different GT3X accelerometer outcome variables assessed using the low frequency extension option. The converted outcome variables can then be compared to results from studies that had used the normal filter option. For the time spent in moderate-to-vigorous physical activity, the correction factors did not improve the comparison.

Paragraph number 23 A limitation of the study was that moderate and vigorous activities could not be analyzed separately as too few individuals engaged in vigorous-intensity 
activities. However, differences were expected especially in the lower range of activity, therefore vigorous-intensity activities were not so much of interest. Even though the sample was not selected representatively, the varying physical activity levels and the wide age range including older adults represent a diverse sample for these analyses. Only data of the vertical axis was analyzed in this study as most researchers still use uniaxial accelerometer data and the additional axes do not seem to improve the estimation of energy expenditure (11). However, further research may investigate the impact of different filter options on threedimensional accelerometer data. The placement of the monitors may play a role for the measurements. However it is most unlikely that placement was responsible for the large differences seen for steps per day and sedentary and light activities as differences were consistently in the same direction and not at random. A further limitation is that the estimates were not compared to a gold standard (e.g. direct observation) as the aim of the study was to investigate differences between filter choices during free-living activities. Future studies may assess differences in a laboratory setting using direct observation as comparison. Finally, the correction factors presented are useful for data analyzed using cut-offs for moderate-tovigorous activities in the range of 2000 counts/minute, such as the NHANES cut-offs (18) or the widely used Freedson cut-offs (8) (SDC Table 1). If using much lower cut-offs (e.g. (16, 22)), however, the correction factors will likely not be appropriate (SDC Table 1).

Paragraph number 24 Recently, the new Actigraph GT3X+ was launched. With these new devices, filter choice and choice of epoch time can be applied after data collection. Further research may investigate how results differ between the different filter options using the GT3X+. However, older versions of the Actigraph are still commonly used and the corrections factors established in the present study will be useful for all studies using the older version $(\mathrm{GT} 3 \mathrm{X})$.

\section{Conclusions}


Paragraph number 25 The present analyses indicate that 1) results for all accelerometer outcome variables differed significantly according to the filter option used, 2) results may not be comparable across studies if different filter options were used. It is therefore recommended 3) to specify the filter option used to collect Actigraph GT3X data in research articles and 4) to carefully evaluate the suitable filter option depending on the research question, study population and necessity of comparability with other studies. For public health research, especially in the field of sedentary behavior and light-intensity physical activity, the differences between filter options found in this study are highly relevant as the calculated activity levels differ widely. This may lead to large amounts of misclassifications of individuals. Finally, if the low frequency extension filter option was used to assess data, the correction factors developed in the present study may be used to convert the accelerometer outcome variables in order to be comparable with data assessed using the normal filter option.

\section{Acknowledgements}

SAPALDIA Team:

Study directorate: Thierry Rochat (p), Jean-Michel Gaspoz (c), Nino Künzli (e/exp), LJ Sally Liu (exp), Nicole M Probst Hensch (e/g), Christian Schindler (s).

Scientific team: Ursula Ackermann-Liebrich (e), Jean-Claude Barthélémy (c), Wolfgang Berger (g), Robert Bettschart (p), Andreas Bircher (a), G Bolognini (p), Otto Brändli (p), Christine Brombach (n), Martin Brutsche (p), Luc Burdet (p), Martin Frey (p), Margaret W Gerbase (p), Diane Gold (e/c/p), Werner Karrer (p), Roland Keller (p), Bruno Knöpfli (p), Brian Martin (pa), Urs Neu (exp), Laurent Nicod (p), Marco Pons (p), Thomas Rothe (p), Erich Russi (p), Peter Schmid-Grendelmeyer (a), Joel Schwartz (e), Diana Stolz (p), Peter 
Straehl (exp), Jean-Marie Tschopp (p), Arnold von Eckardstein (cc), Jean-Pierre Zellweger (p), Elisabeth Zemp Stutz (e).

Scientific team at coordinating centers: Pierre-Olivier Bridevaux (p), Ivan Curjuric (e), Julia Dratva (e), Denise Felber Dietrich (c), Dirk Keidel (s), Susi Kriemler (pa), Medea Imboden (g), Flurina Meier (e), Harish Phuleria (exp), Emmanuel Schaffner (s), Gian-Andri Thun (g), Alex Ineichen (exp), Matthias Ritter (exp).

(a) allergology, (c) cardiology, (cc) clinical chemistry, (e) epidemiology, (exp) exposition, (g) genetics and molecular biology, (m) meteorology, (n) nutrition, (p) pneumology, (s) statistics, (pa) physical activity.

The study could not have been done without the help of the study participants, technical and administrative support and the medical teams and field workers at the local study sites. Local fieldworkers: Aarau: M. Broglie, M. Bünter, D. Gashi, Basel: R. Armbruster, T. Damm, U. Egermann, M. Gut, L. Maier, A. Vögelin, L. Walter, Davos: D. Jud, N. Lutz, Geneva: M. Ares, M. Bennour, B. Galobardes, E. Namer, Lugano: B. Baumberger, S. Boccia Soldati, E. Gehrig-Van Essen, J. Jordan, Wald: R. Gimme, N. Kourkoulos, U. Schafroth. Administration: Nora Bauer, Chantal Gabriel, Rachel Gutknecht.

This study was part of the SAPALDIA Study. The SAPALDIA Study is supported by grants from the Swiss National Science Foundation (grants no 3347CO-108796/1, 3247BO-104283, 3247BO-104288, 3247BO-104284, 32-65896.01, 32-59302.99, 32-52720.97, 32-4253.94, 4026-28099, PDFMP3-123171), by the Federal Office for Forest, Environment and Landscape, the Federal Office of Public Health, the Federal Office of Roads and Transport, the canton's government of Aargau, Basel-Stadt, Basel-Landschaft, Geneva, Ticino, and Zurich, Swiss Lung League, the canton's lung leagues of Basel Stadt/ Basel Landschaft, Geneva, Luzern, Ticino and Zurich. 


\section{Conflicts of interest}

The authors have no conflicts of interest to declare.

The results of the present study do not constitute endorsement by ACSM.

\section{References}

1. Ackermann-Liebrich U, Kuna-Dibbert B, Probst-Hensch NM, Schindler C, Felber Dietrich D, Stutz EZ, Bayer-Oglesby L, Baum F, Brandli O, Brutsche M et al. Followup of the Swiss Cohort Study on Air Pollution and Lung Diseases in Adults (SAPALDIA 2) 1991-2003: methods and characterization of participants. Soz Praventivmed. 2005; 50(4):245-263.

2. ActiGraph R\&D and Software Departments: ActiLife 5 - User's Manual. Volume H. Pensacola: ActiGraph; 2011. p. 16.

3. Buman MP, Hekler EB, Haskell WL, Pruitt L, Conway TL, Cain KL, Sallis JF, Saelens BE, Frank LD, King AC. Objective light-intensity physical activity associations with rated health in older adults. Am J Epidemiol. 2010; 172(10):11551165 .

4. Chaudhury M, Esliger D: Accelerometry in Adults. In Health Survey for England: Physical activity and fitness. Volume 1. Edited by Craig R, Mindell, J., Hirani, V. London: The Health and Social Care Information Centre; 2009. p. 65.

5. Connolly CP, Coe DP, Kendrick JM, Bassett DR, Jr., Thompson DL. Accuracy of physical activity monitors in pregnant women. Med Sci Sports Exerc. 2011; 43(6):1100-1105.

6. Donnelly JE, Blair SN, Jakicic JM, Manore MM, Rankin JW, Smith BK. American College of Sports Medicine Position Stand. Appropriate physical activity intervention strategies for weight loss and prevention of weight regain for adults. Med Sci Sports Exerc. 2009; 41(2):459-471.

7. Esliger DW, Tremblay MS. Physical activity and inactivity profiling: the next generation. Can J Public Health. 2007; 98 Suppl 2:S195-207.

8. Freedson PS, Melanson E, Sirard J. Calibration of the Computer Science and Applications, Inc. accelerometer. Med Sci Sports Exerc. 1998; 30(5):777-781.

9. Gando Y, Yamamoto K, Murakami H, Ohmori Y, Kawakami R, Sanada K, Higuchi M, Tabata I, Miyachi M. Longer time spent in light physical activity is associated with reduced arterial stiffness in older adults. Hypertension. 2010; 56(3):540-546.

10. Hakim AA, Petrovitch H, Burchfiel CM, Ross GW, Rodriguez BL, White LR, Yano $\mathrm{K}$, Curb JD, Abbott RD. Effects of walking on mortality among nonsmoking retired men. $N$ Engl J Med. 1998; 338(2):94-99.

11. Howe CA, Staudenmayer JW, Freedson PS. Accelerometer prediction of energy expenditure: vector magnitude versus vertical axis. Med Sci Sports Exerc. 2009; 41(12):2199-2206. 
12. Kozey-Keadle S, Libertine A, Lyden K, Staudenmayer J, Freedson PS. Validation of wearable monitors for assessing sedentary behavior. Med Sci Sports Exerc. 2011; 43(8):1561-1567.

13. Le Masurier GC, Lee SM, Tudor-Locke C. Motion sensor accuracy under controlled and free-living conditions. Med Sci Sports Exerc. 2004; 36(5):905-910.

14. Le Masurier GC, Tudor-Locke C. Comparison of pedometer and accelerometer accuracy under controlled conditions. Med Sci Sports Exerc. 2003; 35(5):867-871.

15. Lyden K, Kozey SL, Staudenmeyer JW, Freedson PS. A comprehensive evaluation of commonly used accelerometer energy expenditure and MET prediction equations. Eur J Appl Physiol. 2011; 111(2):187-201.

16. Matthews CE. Calibration of accelerometer output for adults. Med Sci Sports Exerc. 2005; 37(11 Suppl):S512-522.

17. Matthews CE, Chen KY, Freedson PS, Buchowski MS, Beech BM, Pate RR, Troiano RP. Amount of time spent in sedentary behaviors in the United States, 2003-2004. Am J Epidemiol. 2008; 167(7):875-881.

18. Metzger JS, Catellier DJ, Evenson KR, Treuth MS, Rosamond WD, Siega-Riz AM. Patterns of objectively measured physical activity in the United States. Med Sci Sports Exerc. 2008; 40(4):630-638.

19. Nagai M, Kuriyama S, Kakizaki M, Ohmori-Matsuda K, Sone T, Hozawa A, Kawado M, Hashimoto S, Tsuji I. Impact of walking on life expectancy and lifetime medical expenditure: the Ohsaki Cohort Study. BMJ Open. 2011; 1(2):bmjopen2011000240.

20. Owen N, Bauman A, Brown W. Too much sitting: a novel and important predictor of chronic disease risk? Br J Sports Med. 2009; 43(2):81-83.

21. Sasaki JE, John D, Freedson PS. Validation and comparison of ActiGraph activity monitors. J Sci Med Sport. 2011; 14(5):411-416.

22. Swartz AM, Strath SJ, Bassett DR, Jr., O'Brien WL, King GA, Ainsworth BE. Estimation of energy expenditure using CSA accelerometers at hip and wrist sites. Med Sci Sports Exerc. 2000; 32(9 Suppl):S450-456.

23. Thorp AA, Owen N, Neuhaus M, Dunstan DW. Sedentary behaviors and subsequent health outcomes in adults a systematic review of longitudinal studies, 1996-2011. Am J Prev Med. 2011; 41(2):207-215.

24. Tremblay MS, Leblanc AG, Kho ME, Saunders TJ, Larouche R, Colley RC, Goldfield G, Gorber SC. Systematic review of sedentary behaviour and health indicators in school-aged children and youth. Int J Behav Nutr Phys Act. 2011; 8:98.

25. Tudor-Locke C, Ainsworth BE, Thompson RW, Matthews CE. Comparison of pedometer and accelerometer measures of free-living physical activity. Med Sci Sports Exerc. 2002; 34(12):2045-2051.

26. Tudor-Locke C, Craig CL, Brown WJ, Clemes SA, De Cocker K, Giles-Corti B, Hatano Y, Inoue S, Matsudo SM, Mutrie N et al. How Many Steps/day are Enough? For Adults. Int J Behav Nutr Phys Act. 2011; 8(1):79.

27. Tudor-Locke C, Hatano Y, Pangrazi RP, Kang M. Revisiting "how many steps are enough?". Med Sci Sports Exerc. 2008; 40(7 Suppl):S537-543.

28. Tudor-Locke C, Johnson WD, Katzmarzyk PT. Accelerometer-determined steps per day in US adults. Med Sci Sports Exerc. 2009; 41(7):1384-1391.

29. World Health Organization: Global Recommendations on Physical Activity for Health. Geneva: WHO; 2010. p. 26. 


\section{Figure Captions}

Figure 1. Scatter plots for comparison of data assessed with normal and with low frequency extension filter options

Figure 2. Bland-Altman plots for the agreement of data assessed with normal and with low frequency extension filter options

Abbreviations: $\mathrm{NF}=$ normal filter, $\mathrm{LF}=$ low frequency extension filter, $\mathrm{SD}=$ standard deviation

\section{Supplemental Digital Content (SDC)}

SDC Figure 1. Scatter plots for comparison of data assessed with normal and with low frequency extension filter options

SDC Figure 2. Bland-Altman plots for the agreement of data assessed with normal and with low frequency extension filter options

Abbreviations: $\mathrm{NF}=$ normal filter, $\mathrm{LF}=$ low frequency extension filter, $\mathrm{SD}=$ standard deviation 
Figure 1
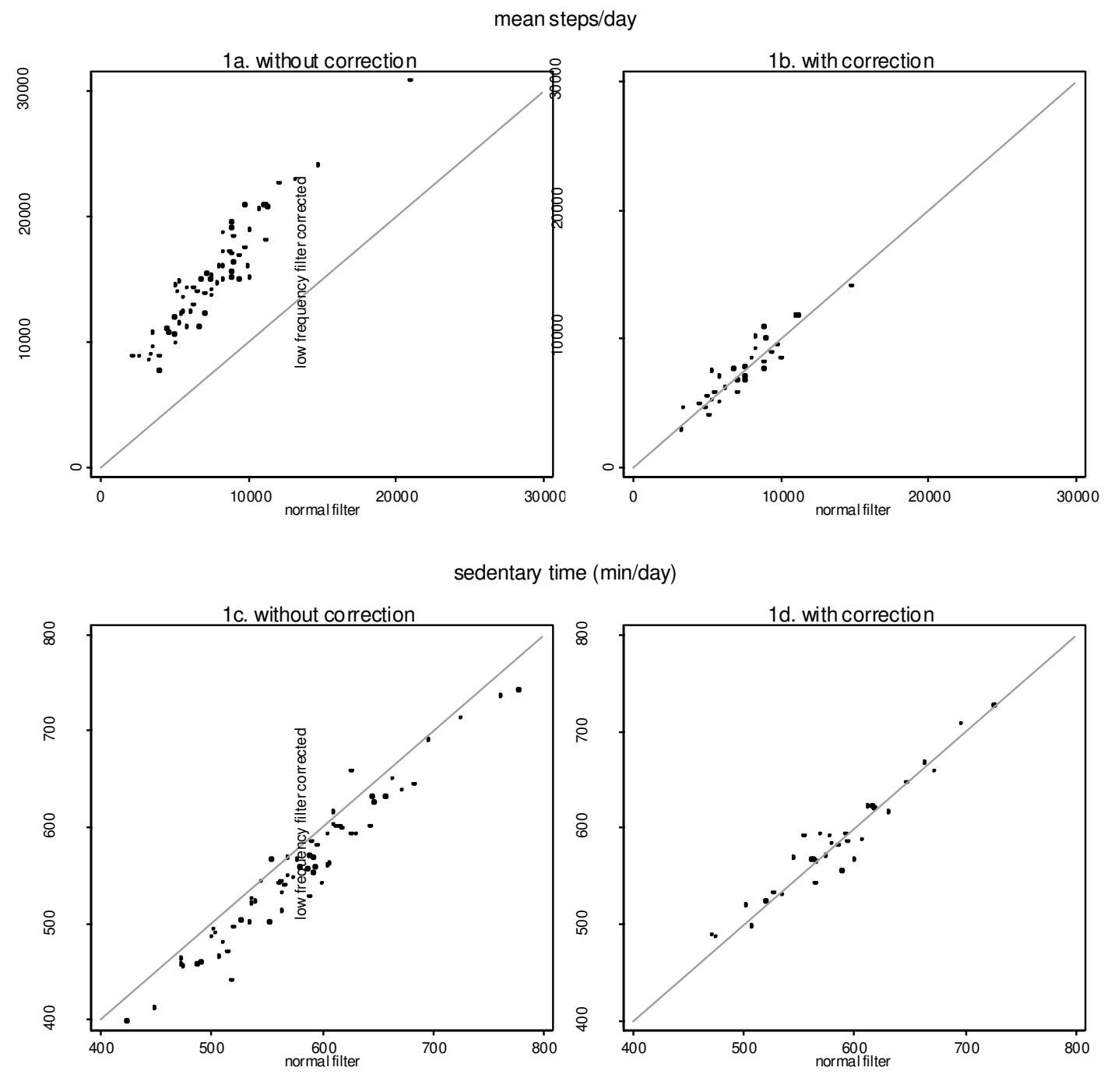

ime (min/day)

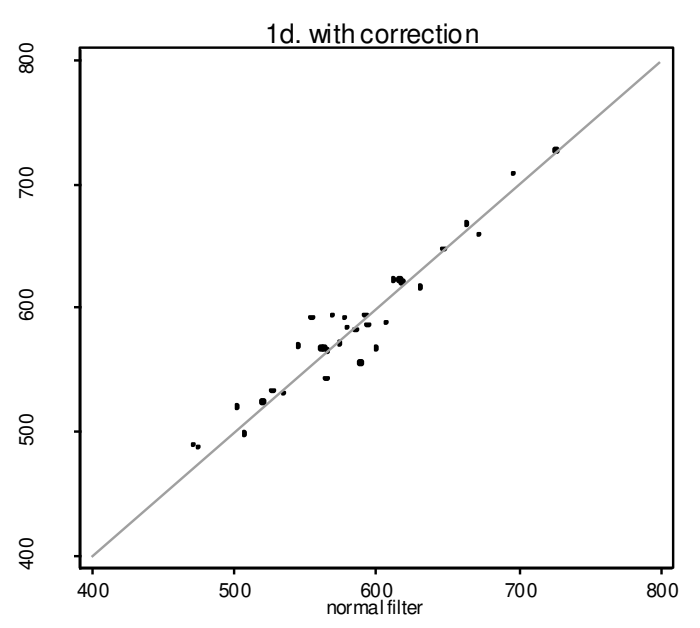

light activities (mindday)
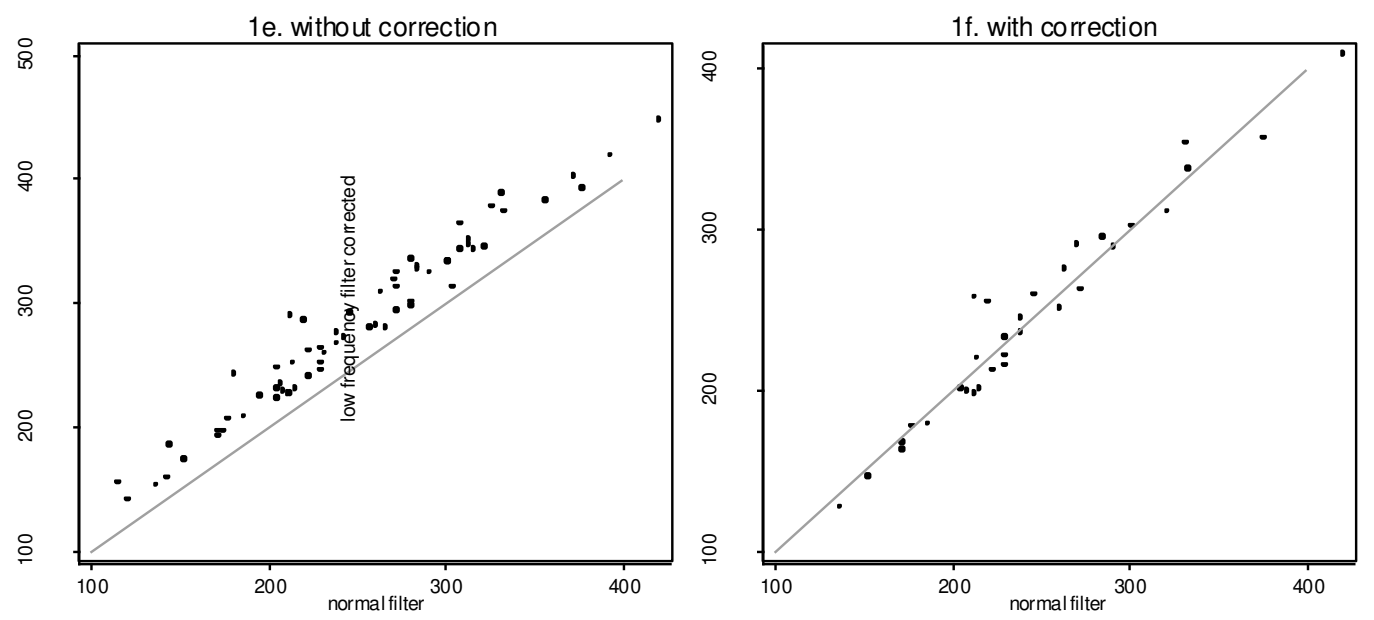
Figure 2
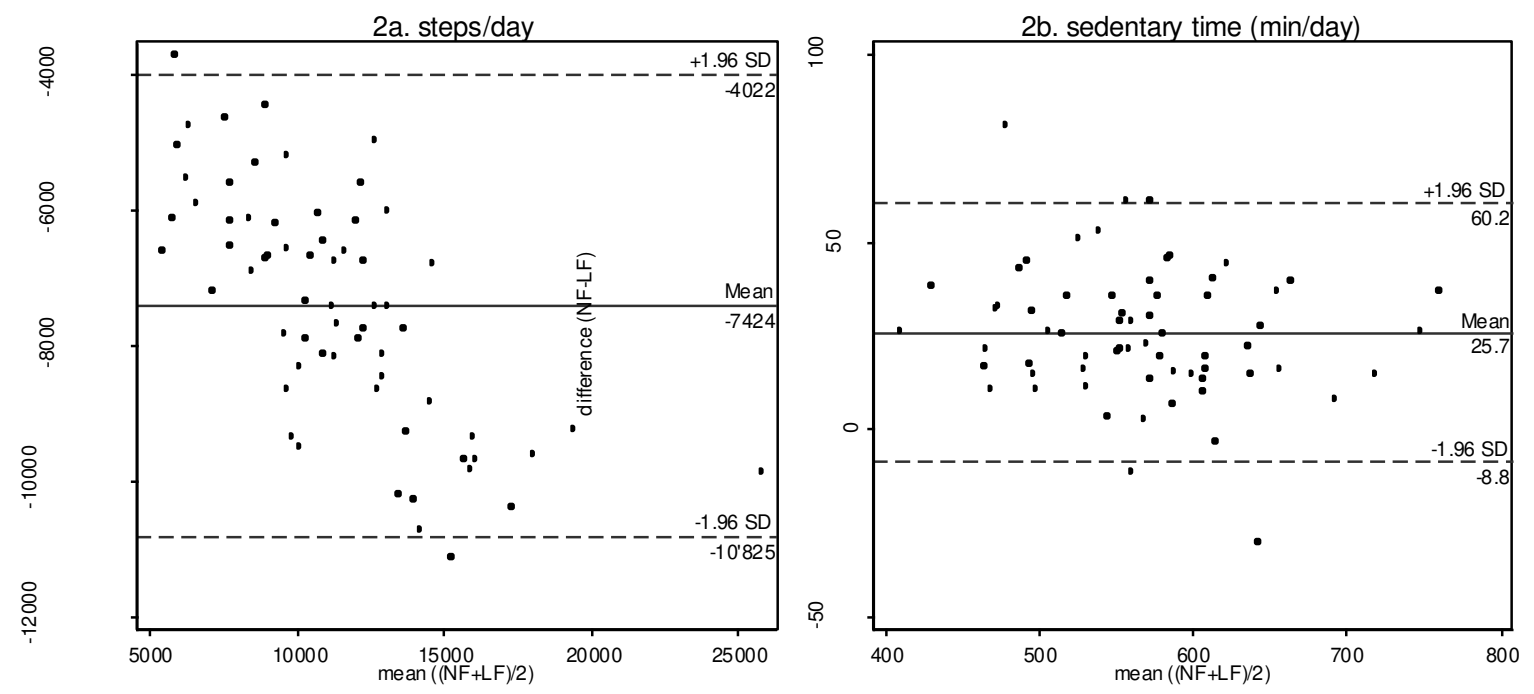
Table 1. Correlations and comparison between data assessed with normal and with low frequency extension filter options $(\mathrm{N}=65)$

\begin{tabular}{|c|c|c|c|c|c|c|c|}
\hline & $\begin{array}{l}\text { Spearman } \\
\mathrm{r}\end{array}$ & $\begin{array}{l}\text { Mean (normal } \\
\text { filter) } \pm \text { SD }\end{array}$ & $\begin{array}{l}\text { Mean (low } \\
\text { frequency } \\
\text { filter) } \pm \text { SD }\end{array}$ & $\begin{array}{l}\text { Mean diff. } \pm \\
\text { SD }\end{array}$ & $\begin{array}{l}\text { Mean diff. in } \\
\%^{1)}\end{array}$ & $\begin{array}{l}\text { Median } \\
\text { diff. }\end{array}$ & $\mathrm{p}$-value \\
\hline $\begin{array}{l}\text { Non-wearing time } \\
(\mathrm{min} / \mathrm{d})\end{array}$ & 0.97 & $579.7 \pm 66.3$ & $570.8 \pm 64.0$ & $8.9 \pm 13.3$ & $1.5 \pm 2.2$ & 7.9 & $<0.001$ \\
\hline $\begin{array}{l}\text { Sedentary time } \\
(\mathrm{min} / \mathrm{d})\end{array}$ & 0.96 & $579.3 \pm 70.0$ & $553.6 \pm 72.9$ & $25.7 \pm 17.6$ & $4.5 \pm 3.1$ & 25.4 & $<0.001$ \\
\hline $\begin{array}{l}\text { Light activities } \\
(\mathrm{min} / \mathrm{d})\end{array}$ & 0.98 & $250.2 \pm 67.1$ & $281.7 \pm 70.1$ & $-31.5 \pm 14.3$ & $-13.4 \pm 7.0$ & -27.6 & $<0.001$ \\
\hline $\begin{array}{l}\text { MVPA activities } \\
(\mathrm{min} / \mathrm{d})\end{array}$ & 0.98 & $30.8 \pm 25.5$ & $33.8 \pm 26.3$ & $-3.1 \pm 3.6$ & $-21.3 \pm 67.7$ & -2.3 & $<0.001$ \\
\hline $\begin{array}{l}\text { Bouts }(\geq 10 \mathrm{~min}) \\
\operatorname{MVPA}(\mathrm{min} / \mathrm{d})\end{array}$ & 0.99 & $15.5 \pm 22.6$ & $16.6 \pm 22.8$ & $-1.0 \pm 2.2$ & $-18.4 \pm 38.4$ & -0.1 & $<0.001$ \\
\hline Steps/day & 0.93 & $7696 \pm 3132.1$ & $\begin{array}{l}15^{\prime} 119 \pm \\
4329.9\end{array}$ & $-7424 \pm 1736$ & $-108.4 \pm 43.2$ & -7353 & $<0.001$ \\
\hline Mean counts/min & 0.99 & $308.9 \pm 135.4$ & $346.7 \pm 140.2$ & $-37.8 \pm 19.5$ & $-13.7 \pm 7.3$ & -37.7 & $<0.001$ \\
\hline
\end{tabular}

${ }^{1)}$ denominators were the time $(\mathrm{min} / \mathrm{d})$, steps/day and counts/min, respectively, recorded by the normal filter 
Table 2. Correction factors based on linear regression $(\mathrm{N}=33)$

\begin{tabular}{|l|l|}
\hline Outcome variables & Correction factors (linear \\
regression) \\
\hline Non-wearing time & $2.996+1.01 *$ non-wearing \\
time $(\mathrm{LF})$
\end{tabular}

Abbreviations: $\mathrm{LF}=$ low frequency extension filter, MVPA = moderate-to-vigorous physical activity; $\min / \mathrm{d}=$ minutes per day 
Table 3. Correlations and comparison between data assessed with normal and with low frequency extension filter options using correction factors $(\mathrm{N}=32)$

\begin{tabular}{|c|c|c|c|c|c|c|}
\hline & $\begin{array}{l}\text { Mean (normal } \\
\text { filter) } \pm \mathrm{SD}\end{array}$ & $\begin{array}{l}\text { Mean (low } \\
\text { frequency filter) } \\
\pm \text { SD }\end{array}$ & Mean diff. \pm SD & $\begin{array}{l}\text { Mean diff. in } \\
\%^{1)}\end{array}$ & $\begin{array}{l}\text { Median } \\
\text { diff. }\end{array}$ & p-value \\
\hline $\begin{array}{l}\text { Non-wearing time } \\
(\mathrm{min} / \mathrm{d})\end{array}$ & $580.0 \pm 58.2$ & $580.7 \pm 56.8$ & $-0.8 \pm 9.1$ & $-0.2 \pm 1.5$ & -1.3 & 0.30 \\
\hline $\begin{array}{l}\text { Sedentary time } \\
(\mathrm{min} / \mathrm{d})\end{array}$ & $583.5 \pm 59.0$ & $583.4 \pm 57.0$ & $0.1 \pm 15.6$ & $-0.1 \pm 2.7$ & -2.8 & 0.72 \\
\hline $\begin{array}{l}\text { Light activities } \\
(\mathrm{min} / \mathrm{d})\end{array}$ & $245.5 \pm 63.6$ & $245.2 \pm 65.2$ & $0.3 \pm 14.8$ & $0.26 \pm 6.4$ & 4.1 & 0.41 \\
\hline $\begin{array}{l}\text { MVPA activities } \\
(\mathrm{min} / \mathrm{d})\end{array}$ & $31.1 \pm 27.2$ & $30.5 \pm 26.5$ & $0.6 \pm 2.8$ & $-5.6 \pm 54.5$ & 1.1 & 0.045 \\
\hline $\begin{array}{l}\text { Bouts }(\geq 10 \mathrm{~min}) \\
\operatorname{MVPA}(\mathrm{min} / \mathrm{d})\end{array}$ & $15.4 \pm 24.7$ & $15.4 \pm 24.6$ & $0.1 \pm 1.4$ & $-6.0 \pm 32.1$ & 0.8 & 0.12 \\
\hline Steps/day & $7456 \pm 2464$ & $7482 \pm 2533$ & $-26 \pm 973$ & $-0.9 \pm 14.5$ & 58 & 0.93 \\
\hline Mean counts/min & $303.5 \pm 121.4$ & $301.0 \pm 121.8$ & $2.5 \pm 15.9$ & $1.0 \pm 6.4$ & 1.9 & 0.35 \\
\hline
\end{tabular}

${ }^{1)}$ denominators were the time $(\mathrm{min} / \mathrm{d})$, steps/day and counts/min, respectively, recorded by the normal filter Abbreviations: $\mathrm{MVPA}=$ moderate-to-vigorous physical activity $; \min / \mathrm{d}=$ minutes per day, $\mathrm{SD}=$ standard deviation; diff. $=$ difference 
SDC 1 (Figure)
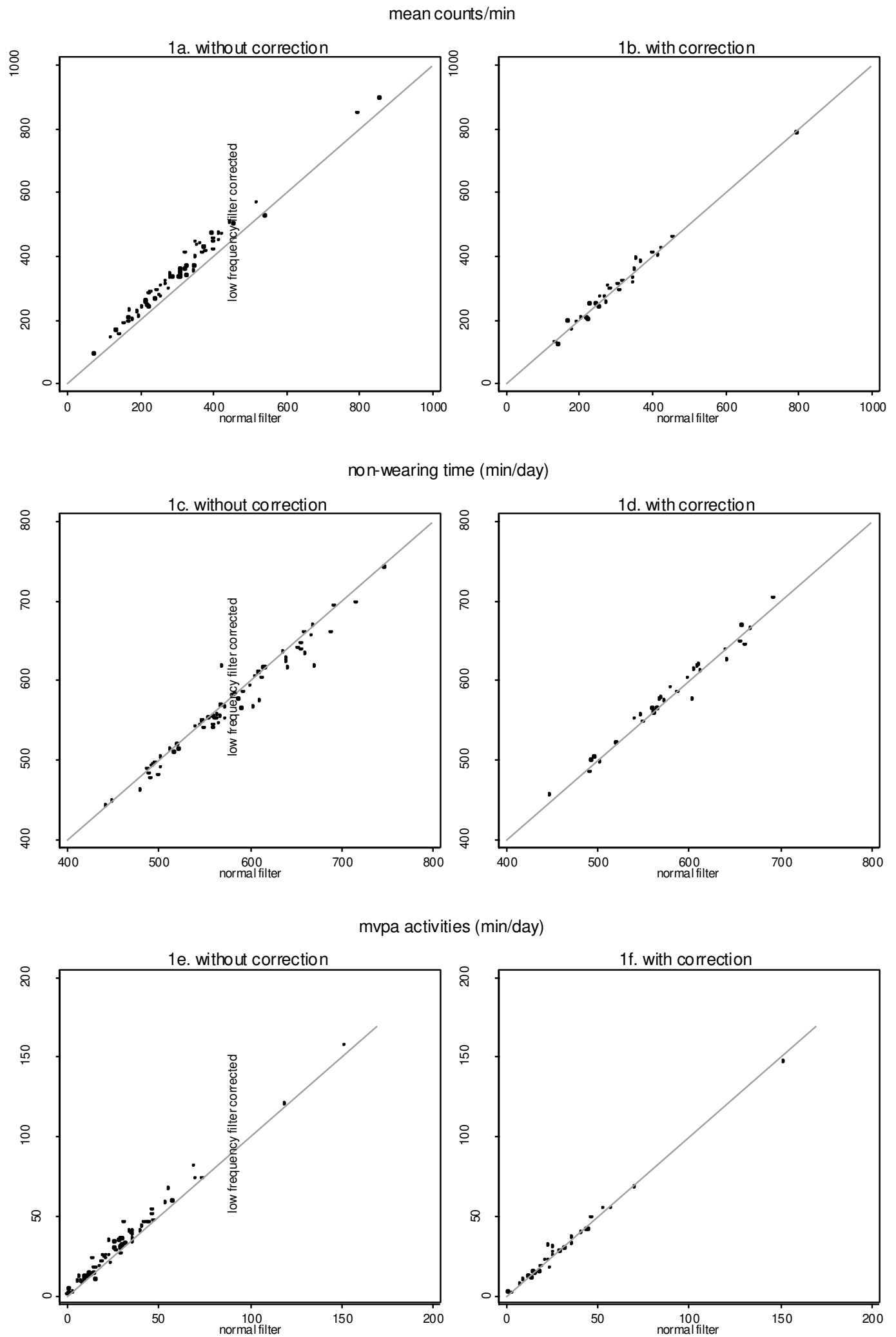

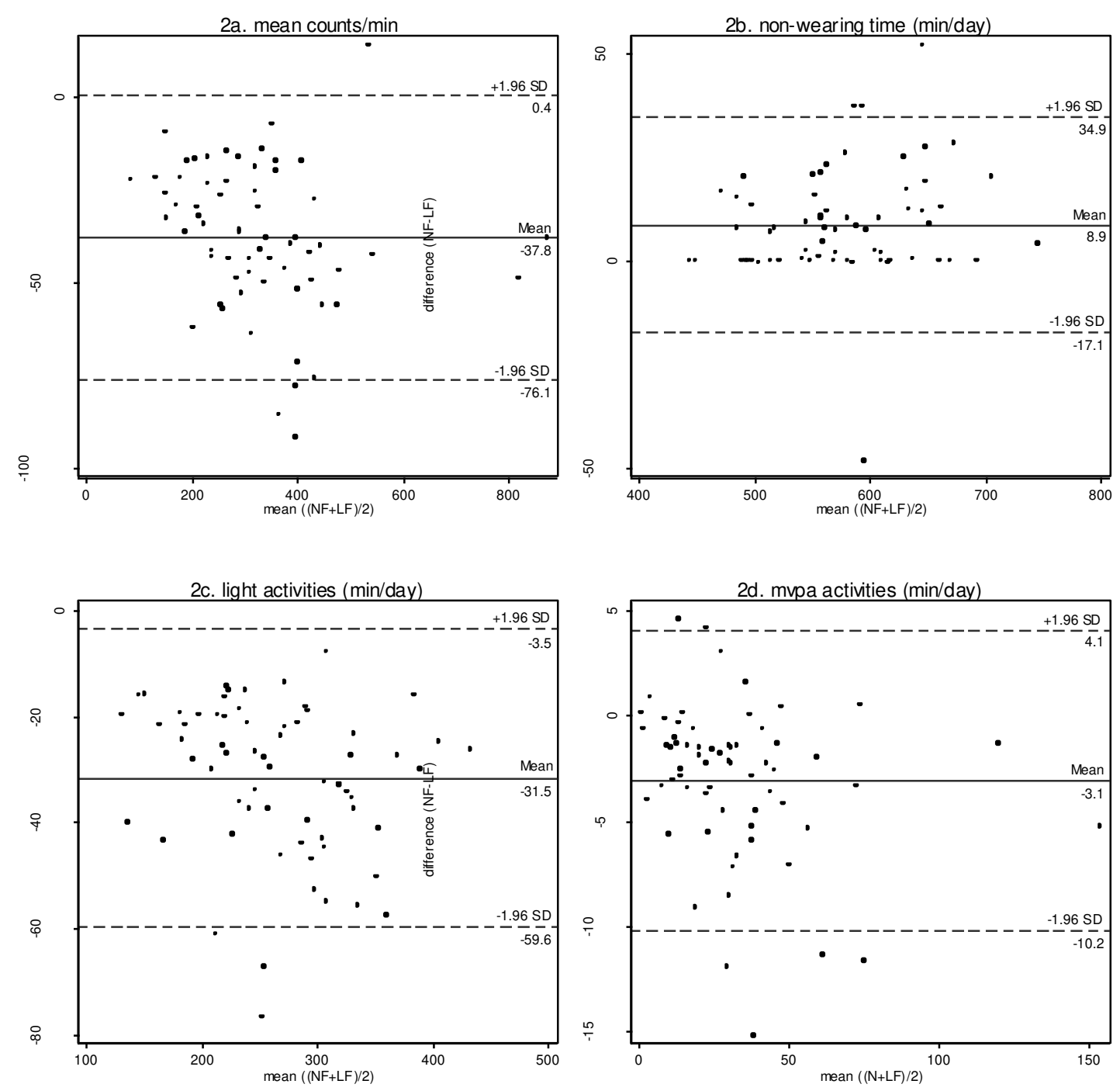
SDC 3 (Table). Comparison between data assessed with normal and with low frequency extension filter options analyzed based on different cut-offs (Freedson et al 1998; Matthews et al. 2005) using correction factors developed based on data analyzed with the NHANES cut-offs $(\mathrm{N}=32)$

\begin{tabular}{|c|c|c|c|c|c|c|}
\hline & $\begin{array}{l}\text { Mean (normal } \\
\text { filter) } \pm \mathrm{SD}\end{array}$ & $\begin{array}{l}\text { Mean (low } \\
\text { frequency filter) } \\
\pm \text { SD }\end{array}$ & Mean diff. \pm SD & $\begin{array}{l}\text { Mean diff. in } \\
\%^{1)}\end{array}$ & $\begin{array}{l}\text { Median } \\
\text { diff. }\end{array}$ & $\mathrm{p}$-value \\
\hline \multicolumn{7}{|c|}{ Freedson (1998) cut-offs for mvpa ( $\geq 1952 \mathrm{cpm})$} \\
\hline $\begin{array}{l}\text { Light activities } \\
(\mathrm{min} / \mathrm{d})\end{array}$ & $244.0 \pm 63.2$ & $243.7 \pm 65.0$ & $0.3 \pm 14.9$ & $0.3 \pm 6.5$ & 4.1 & 0.38 \\
\hline $\begin{array}{l}\text { MVPA activities } \\
(\mathrm{min} / \mathrm{d})\end{array}$ & $32.6 \pm 27.5$ & $32.0 \pm 26.8$ & $0.6 \pm 2.9$ & $-4.8 \pm 48.6$ & 0.7 & 0.10 \\
\hline $\begin{array}{l}\text { Bouts }(\geq 10 \mathrm{~min}) \\
\operatorname{MVPA}(\mathrm{min} / \mathrm{d})\end{array}$ & $15.8 \pm 25.0$ & $16.0 \pm 25.2$ & $-0.2 \pm 1.2$ & $-4.5 \pm 24.7$ & 0.4 & 0.87 \\
\hline \multicolumn{7}{|c|}{ Matthews (2005) cut-offs for mvpa ( $\geq 760 \mathrm{cpm})$} \\
\hline $\begin{array}{l}\text { Light activities } \\
(\mathrm{min} / \mathrm{d})\end{array}$ & $175.4 \pm 41.6$ & $165.6 \pm 43.3$ & $9.8 \pm 14.8$ & $5.9 \pm 8.1$ & 13.6 & 0.0008 \\
\hline $\begin{array}{l}\text { MVPA activities } \\
(\mathrm{min} / \mathrm{d})\end{array}$ & $101.1 \pm 44.2$ & $109.0 \pm 44.0$ & $-7.9 \pm 9.7$ & $-9.5 \pm 13.30$ & -5.3 & 0.0001 \\
\hline $\begin{array}{l}\text { Bouts }(\geq 10 \mathrm{~min}) \\
\operatorname{MVPA}(\mathrm{min} / \mathrm{d})\end{array}$ & $36.6 \pm 33.3$ & $41.1 \pm 33.5$ & $-4.5 \pm 6.2$ & $-18.7 \pm 34.3$ & -2.4 & 0.0001 \\
\hline
\end{tabular}

${ }^{1)}$ denominators were the time $(\mathrm{min} / \mathrm{d})$, steps/day and counts/min, respectively, recorded by the normal filter 